\title{
Impact of Parent's Socioeconomic Status on Perceived Parental Pressure and Test Anxiety among Chinese High School Students
}

\author{
Huilin Chen ${ }^{1}$ \\ ${ }^{1}$ College of International Education, Shanghai Internbational Studies University, Shanghai, China \\ Correspondence: Huilin Chen, College of International Education, Shanghai Internbational Studies University, \\ Shanghai, 200083, China. E-mail: chlmailbox@gmail.com
}

Received: April 6, 2012 Accepted: April 19, 2012 Published: June 1, 2012

doi:10.5539/ijps.v4n2p235 URL: http://dx.doi.org/10.5539/ijps.v4n2p235

This research is financed by Shanghai International Studies University, Shanghai China, and is a partial fulfillment of the project "Language and Test Anxiety" (211 YYCHL01).

\begin{abstract}
This study carries out empirical researches among Mainland Chinese high school students to explore the impact of parent's socioeconomic status on perceived parental pressure and test anxiety. The discoveries of the study include: perceived parental pressure has significant impact on test anxiety; parents' occupations, parents' income and mother's education have significant impact on perceived parental pressure; parents' occupations, parents' income and mother's education have significant impact on test anxiety. There are sufficient evidences to support the notion that the ethic stressing family glory and material success can be a major source of perceived parental pressure and test anxiety in China. Another finding of the study is that there may exist a mediation relationship among parent's socioeconomic status, perceived parental pressure, and test anxiety. By controlling perceived parental pressure, the mediator variable, the impact of parent's socioeconomic status on test anxiety can be greatly reduced.
\end{abstract}

Keywords: parent's socioeconomic status, perceived parental pressure, test anxiety, Chinese high school students, mediation relationship, family glory

\section{Introducation}

Since filial piety, obedience, negation of conflict and reverence for parents and tradition are the core values of Chinese families ( $\mathrm{Lin} \& \mathrm{Fu}, 1990$ ), Chinese children tend to perceive more parental pressure than their counterparts from Western countries do (Chan, 1995; Crystal et al, 1994). Although a few studies discovered the relationship between parental pressure and test anxiety (Pang, 1991; Singh \& Broota, 1992; Putwain, Woods, \& Symes, 2010), they haven't dug deep into the factors determining the degree of perceived parental pressure. This article puts emphasis on exploring the impact of parent's socioeconomic status on both perceived parental pressure and test anxiety.

Test anxiety is defined as the anxiety subjectively relating to taking tests and exams, including anxiety related to the threat of failing an exam and the associated negative consequences such as psychological hyperarousal, negative thought patterns, a desire to escape from or avoid evaluative situations, inadequate performance on a test or other evaluation and difficulty in focusing on the task at hand, regardless of whether the fears were realistic (Sarason 1984: 930; Pekrun et al. 2004: 290; Hopko, Hunt, \& Armento, 2005: 389-408). The relationship between test anxiety and test performance can be regarded as monotonically negative or even linear. That is, as test anxiety increases, performance is expected to decrease (Rocklin \& Thompson 1985; Bodas \& Ollendick, 2005).

A great deal of literature has established how test anxiety is influenced by both characteristics of the evaluative situation and personal factors. Zeidner's (1998) transactional process model of test anxiety specifies the following characteristics of the evaluative situation: nature of the task, difficulty, atmosphere, time constraints, examiner characteristics, mode of administration, and physical setting, and the following personal characteristics: trait test anxiety, need for achievement, self-efficacy, scholastic ability, information-processing capacity, study skills, and test-wiseness. Putwain (2007) reported that age, gender, ethnic, and socioeconomic background were significant predictors of test anxiety scores. 
According to Putwain (2009), parental pressure is a factor related with students' socioeconomic background which may affect test anxiety. Parents are perceived as sources of pressure by students when they communicate messages perceived by the student as emphasizing conditions of acceptance based on achievement in examinations and others assessments, rather than the effort made. It is therefore, no surprise that perceived parental pressure is associated with poor social and academic adjustment (Baumrind, 1978; Campbell \& Mandell, 1990; Maccoby \& Martin, 1983) and an increase in test anxiety (Singh \& Broota, 1992).

The impact of parental pressure on test anxiety is even greater in Asian countries. The ethic of Asian people stresses on family glory, filial piety, and a belief in the efficiency of effort and hard work. Attaining high scholastic achievements is one major way children have of repaying their infinite debt to their parents and of showing filial piety. That is to say, the students work not only for themselves, but also for their family's honor. The stress on academic excellence in Asian families, as manifested in the strong parental pressures to succeed in the academic sphere, may place these students under considerable psychological stress. This constant pressure to succeed in school has been hypothesized to play a role in the development of test anxiety (Dion \& Toner, 1988; Pang, 1991). Dion and Toner (1988) provided data in support of the claim that in North America individuals of Asian descent are more prone to be stressed in evaluative situations than are their counterparts of European descent. Similarly, Pang (1991) reported higher levels of test anxiety in Asian Americans compared to White children enrolled in middle school. Students' perception of pleasing parents and parental pressures was significantly related to test anxiety, with Asian-American students aiming more than their counterparts at pleasing their parents.

As mentioned above, perceived parental pressure may vary among different cultures and ethnic traditions. Cultures stressing family glory, filial piety, and obedience may cause higher degree of perceived parental pressure. But in the same culture, what determines the degree of perceived parental pressure? Few studies were conducted to explore the valuables determining the degree of parental pressure in the same culture except for the unpublished study conducted by Pamela J. Riley (2003) who collected the demographic statistics of adolescents and their parents in Beijing China. These demographic variables included adolescent's gender, parent's gender, parent's educational and income level, parent's occupation, adolescent's age, adolescent's grade in high school, adolescent's academic performance, adolescent's type of school, and adolescent desire for a university education. But the statistics about parental educational level, occupation, and income level were not examined for the correlation with parental pressure and further research was suggested. Since parent's educational level, occupation, and income level can fall into the category of parent's socioeconomic status, there is a need to explore the relationship between parent's socioeconomic status and perceived parental pressure.

According to the literature review, research insufficiency can be found in the previous relevant studies. First, although the previous studies about the relationship between parental pressure and test anxiety were conducted from a cross-cultural viewpoint, none of them made investigations among the Chinese in Mainland China. Second, few studies were concerned with the factors determining the degree of parental pressure. Third, no study has been conducted to investigate the relationship among parent's socioeconomic status, perceived parental pressure, and test anxiety. Therefore, this study proposes three hypotheses. They are as follows,

1) Perceived parental pressure has significant impact on test anxiety among Mainland Chinese high school students.

2) Factors concerning parent's socioeconomic status may determine the degree of perceived parental pressure among Mainland Chinese high school students.

3) Parent's socioeconomic status has significant impact on test anxiety among Mainland Chinese high school students.

\section{Research Design}

\subsection{Participants}

The sample consists of 337 students attending high schools in Shanghai, China. They come from 7 high schools among which 4 high schools are located in urban Shanghai and 3 others in suburban Shanghai. Students are all from grade Senior 3 which is the final grade for high schools in China. From each high school, one Senior 3 class is randomly selected to be included into the sample. The reason why Senior 3 students are adopted as the sample lies in the fact that those students are facing College Entrance Examination, a testing program with the highest stake in China, and thus may perceive more parental pressure than students from other grades.

For the consistency of statistical analysis, the data of the students who fail to provide complete information are labeled as invalid data and are not analyzed in the research. Since Armed Forces Occupations are special 
occupations, the data of the students who provide information of Armed Forces Occupations are not analyzed in the research either. Therefore, the actual sample whose data are analyzed in the research includes 294 Senior 3 high school students.

\subsection{Instruments}

The major instruments employed in this study include Test Anxiety Inventory (TAI) (Spielberger 1980) and the Chinese version translated by Ye (1988), Inventory of Parental Influence (IPI; Campbell, 1994) and the Chinese version adopted in the unpublished study conducted by Pamela J. Riley (2003), Sobel Test Calculator for the Significance of Mediation (Soper, 2012), Questionnaire of Parent's Socioeconomic Status, and the data analysis software SPSS.

Test anxiety of the subjects is measured by using Test Anxiety Inventory, a self-report inventory. The inventory was designed by Charles D. Spielberger (1980) to measure individual differences in test anxiety and is the most frequently used scale in worldwide test anxiety research. An unpublished study conducted by Ling (2007) showed that the coefficient alpha reliability for the Chinese version TAI total scale was .909 among Chinese high school students. TAI consists of 20 items of statements, and the respondents indicate on a four-point Likert scale how often they experience the feeling described in each statement. Since each item has four choices, the minimum TAI total score is 20 and the maximum is 80 , with a higher score indicating higher test anxiety.

Parental pressure is measured by using a subscale of the Inventory of Parental Influence (IPI; Campbell, 1994). The IPI consists of a series of subscales and only the subscale related to parental pressure was used for this study, to identify students' perceptions of the pressure that they perceive from their parents to achieve academically. Campbell made modifications to the original instrument during tests with students and parents in China, to reflect items that were ambiguous in the local setting, reducing the number of questions on parental pressure from thirteen to nine. The coefficient alpha reliability for the parental pressure factor is .83 . The IPI parental pressure factor consists of 9 statements to which respondents express their degree of agreement or disagreement in a five-point Likert format. Since each item has five choices, the minimum IPI parental pressure factor score is 9 and the maximum is 45 , with a higher score indicating perceptions of more demanding parents who exert pressure to retain high levels of performance.

Sobel Test Calculator for the Significance of Mediation (Soper, 2012), based on Sobel Test (Sobel, 1982), is used to prove the probable existence of a mediation relationship among parent's socioeconomic status, perceived parental pressure and test anxiety. The Calculator can tell whether the mediator variable (perceived parental pressure) significantly carries the influence of an independent variable (parent's socioeconomic status) to a dependent variable (test anxiety). The regression coefficient for the association between independent valuable and mediator, the regression coefficient for the association between the mediator and the dependent valuable, and the standard errors of the two regression coefficients are concerned with in the computation of Sobel Test.

Information of parent's socioeconomic status is gathered by means of completing the Questionnaire of Parent's Socioeconomic Status which collects information of parent's gender, parent's occupation, parent's educational level, and parents' income.

According to the ISCO-08 (2008) structure (Note 1), occupations worldwide can be divided into 10 major groups. They are Managers (including both government officials and business managers), Professionals, Technicians and Associate Professionals, Clerical Support Workers, Service and Sales Workers, Skilled Agricultural, Forestry and Fishery Workers, Craft and Related Trades Workers, Plant and Machine Operators, and Assemblers, Elementary Occupations, and Armed Forces Occupations. Therefore, the occupation information section of Questionnaire of Parent's Socioeconomic Status contains those 10 choices of occupation types.

The education information section of Questionnaire of Parent's Socioeconomic Status gives students 4 choices. They are: Postgraduate Level (including doctoral and master degree education), College Education Level (including bachelor's degree and associate degree education), Secondary Education Level (including senior secondary, junior secondary and vocational education), and Primary Education Level.

The income information section of Questionnaire of Parent's Socioeconomic Status collects information of the total annual income of both parents. There are also 4 choices: Over RMB 300 000, RMB 150000 - RMB 300 000, RMB 50000 - RMB 150 000, and Below RMB 50 000. The exchange rate is about USD $\$ 1.00=$ RMB 6.5.

All the inventories and the questionnaire adopted in this research are in Chinese version.

\subsection{Procedure}

The inventories and the questionnaire are handed out to the sample students at different time so as to avoid the 
interactional influence of completing different forms.

Questionnaires of Parent's Socioeconomic Status are first handed out to the sample students mainly to collect the information of parent's socioeconomic status. As for the occupation information section, the sample students are given 10 choices of occupational types based on ISCO-08. Information of both father's occupation and mother's occupation is collected. For the sake of conciseness and clarity of the research, the 10 occupational types are further grouped into 4 major types in the statistical analysis. They four major occupational types are listed as follows,

1) Managers (including both government officials and business managers)

2) White Collar Occupations: Professionals, Technicians and Associate Professionals, Clerical Support Workers, and Service and Sales Workers.

3) Blue Collar Occupations: Craft and Related Trades Workers, Plant and Machine Operators, and Assemblers, and part of Elementary Occupations.

4) Agriculture-related Occupations: Skilled Agricultural, Forestry and Fishery Workers, and part of Elementary Occupations.

Armed Forces Occupations are not taken into consideration in this study. As for the education information section, information of both father's and mother's education level is collected. As for the income information section, information of the total annual income of both parents is collected. The data of the students who fail to provide complete information in Questionnaire of Parent's Socioeconomic Status are labeled as invalid data and are not analyzed in the research.

One month after the completion of Questionnaire of Parent's Socioeconomic Status, the sample students are requested to complete Inventory of Parental Influence parental pressure factor. One month after the completion of Parental Influence parental pressure factor, the sample students are requested to complete Inventory of Test Anxiety. All statistical analyses focus on the actual sample of the 294 students. A linear regression analysis is computed to test the impact of perceived parental pressure (Independent Valuable) as assessed by the IPI parental pressure factor on test anxiety (Dependent Valuable) as assessed by the TAI. A multivariate analysis of variance is computed to test the impact of father's occupation, mother's occupation, father's educational level, mother's educational level, and parents' income (Factors) as collected by Questionnaire of Parent's Socioeconomic Status on perceived parental pressure (Dependent Valuable) as assessed by the IPI parental pressure factor and test anxiety as assessed by the TAI. A Sobel test is further conducted to examine the possible existence of a mediation relationship among parent's socioeconomic status, perceived parental pressure and test anxiety.

\section{Results}

\subsection{Impact of Perceived Parental Pressure on Test Anxiety}

To examine the impact of perceived parental pressure on test anxiety, a linear regression analysis is computed. In the analysis, the perceived parental pressure assessed by the IPI parental pressure factor is selected as Independent Valuable and test anxiety assessed by the TAI is selected as Dependent Valuable.

According to the correlation table, a high positive correlation between test anxiety and perceived parental pressure $(r=.861, p=.000)$ is found. According to the ANOVA table, linear relationship between perceived parental pressure and test anxiety is also discovered since sum of squares of regression is 23481.577 which is much bigger than that of residual and the significance $p$-value is much smaller than .01 . According to table of model summary, high degree of linear fit is demonstrated since $R^{2}=.741$ which shows that the regression model can explain more than $70 \%$ of the variations in test anxiety. The coefficients of the fit line are shown in Table 1 .

Table 1. Regression Coefficients concerning perceived parental pressure and test anxiety

\begin{tabular}{lccccccc}
\hline \multicolumn{1}{c}{ Model } & \multicolumn{2}{c}{$\begin{array}{c}\text { Unstandardized } \\
\text { Coefficients }\end{array}$} & $\begin{array}{c}\text { Standardized } \\
\text { Coefficients }\end{array}$ & $t$ & $p$ & \multicolumn{2}{c}{$\begin{array}{c}\text { Collinearity } \\
\text { Statistics }\end{array}$} \\
\hline & B & Std. Error & Beta & & & Tolerance & VIF \\
(Constant) & 21.931 & 1.276 & & 17.187 & .000 & & \\
$\begin{array}{l}\text { perceived parental } \\
\text { pressure }\end{array}$ & 1.189 & .041 & .861 & 28.886 & .000 & 1.000 & 1.000 \\
\hline
\end{tabular}


Both the coefficient of perceived parental pressure and the constant are significant statistically $(p<.01)$. The linear relationship between perceived parental pressure (Independent Valuable) and test anxiety (Dependent Valuable) can be expressed in the function below.

$$
\text { Test Anxiety }=1.189 \times \text { Perceived Parental Pressure }+21.931
$$

\subsection{Impact of Parent's Socioeconomic Status on Perceived Parental Pressure and Test Anxiety}

To examine the impact of parent's socioeconomic status on perceived parental pressure and test anxiety, a multivariate analysis of variance is computed. In the analysis, father's occupation, mother's occupation, father's educational level, mother's education level, and parents' income collected by Questionnaire of Parent's Socioeconomic Status are selected as Factors, and perceived parental pressure assessed by the IPI parental pressure factor and test anxiety assessed by the TAI are selected as Dependent Valuable. The results of the analysis are shown in Table 2 and Table 3.

Table 2. Descriptive statistics and coding about between-subjects factors

\begin{tabular}{llrrr}
\hline & & Coding & $N$ & $\%$ \\
\hline father's occupation & managers & 1 & 43 & $14.63 \%$ \\
& white collar occupations & 2 & 121 & $41.16 \%$ \\
& blue collar occupations & 3 & 86 & $29.25 \%$ \\
& agriculture-related occupations & 4 & 44 & $14.97 \%$ \\
mother's occupation & managers & 1 & 51 & $17.35 \%$ \\
& white collar occupations & 2 & 79 & $26.87 \%$ \\
& blue collar occupations & 3 & 111 & $37.76 \%$ \\
father's education & agriculture-related occupations & 4 & 53 & $18.03 \%$ \\
& postgraduate level & 1 & 43 & $14.63 \%$ \\
& college education level & 2 & 116 & $39.46 \%$ \\
mother's education & secondary education level & 3 & 116 & $39.46 \%$ \\
& primary education level & 4 & 19 & $6.46 \%$ \\
& postgraduate level & 1 & 10 & $3.40 \%$ \\
& college education level & 2 & 96 & $32.65 \%$ \\
& secondary education level & 3 & 149 & $50.68 \%$ \\
& primary education level & 4 & 39 & $13.27 \%$ \\
& over RMB 300000 & 1 & 41 & $13.95 \%$ \\
& RMB 150000 - RMB 300000 & 2 & 129 & $43.88 \%$ \\
& RMB 50000 - RMB 150000 & 3 & 97 & $32.99 \%$ \\
& below RMB 50000 & 4 & 27 & $9.18 \%$ \\
\hline
\end{tabular}

Table 2 shows the descriptive statistics of the Factors and the coding of the categories within each Factor in the multivariate analysis of variance. The $p$-value of the Box's test is .092 which is greater than .05 , suggesting that the observed covariance matrices of the dependent variables are equal across groups, and thus the model results are valid. Table 3 demonstrates the effects of parent's socioeconomic status on test anxiety and perceived parental pressure. 
Table 3. Tests of between-subjects effects of the multivariate analysis of variance

\begin{tabular}{|c|c|c|c|c|c|c|c|}
\hline Source & Dependent & $\begin{array}{l}\text { Type III Sum of } \\
\text { Squares }\end{array}$ & $d f$ & $\begin{array}{l}\text { Mean } \\
\text { Square }\end{array}$ & $F$ & $p$ & $\begin{array}{l}\text { Partial Eta } \\
\text { Squared }\end{array}$ \\
\hline \multirow[t]{2}{*}{ father's occupation } & test anxiety & 1439.211 & 3 & 479.737 & 8.292 & .000 & .138 \\
\hline & $\begin{array}{l}\text { perceived } \\
\text { parental pressure }\end{array}$ & 335.323 & 3 & 111.774 & 3.417 & .019 & .062 \\
\hline \multirow[t]{2}{*}{ mother's occupation } & test anxiety & 827.703 & 3 & 275.901 & 4.769 & .003 & .084 \\
\hline & $\begin{array}{l}\text { perceived } \\
\text { parental pressure }\end{array}$ & 376.49 & 3 & 125.497 & 3.837 & .011 & .069 \\
\hline \multirow[t]{2}{*}{ father's education } & test anxiety & 349.102 & 3 & 116.367 & 2.011 & .115 & .037 \\
\hline & $\begin{array}{l}\text { perceived } \\
\text { parental pressure }\end{array}$ & 65.118 & 3 & 21.706 & .664 & .576 & .013 \\
\hline \multirow[t]{2}{*}{ mother's education } & test anxiety & 517.085 & 3 & 172.362 & 2.979 & .033 & .054 \\
\hline & $\begin{array}{l}\text { perceived } \\
\text { parental pressure }\end{array}$ & 263.642 & 3 & 87.881 & 2.687 & .048 & .049 \\
\hline \multirow[t]{2}{*}{ parents' income } & test anxiety & 774.752 & 3 & 258.251 & 4.464 & .005 & .079 \\
\hline & $\begin{array}{l}\text { perceived } \\
\text { parental pressure }\end{array}$ & 643.385 & 3 & 214.462 & 6.557 & .000 & .112 \\
\hline \multirow{2}{*}{$\begin{array}{l}\text { father's occupation * } \\
\text { mother's occupation }\end{array}$} & test anxiety & 659.668 & 8 & 82.458 & 1.425 & .190 & .068 \\
\hline & $\begin{array}{l}\text { perceived } \\
\text { parental pressure }\end{array}$ & 250.559 & 8 & 31.320 & .958 & .471 & .047 \\
\hline \multirow{2}{*}{$\begin{array}{l}\text { father's education * } \\
\text { mother's education }\end{array}$} & test anxiety & 78.088 & 5 & 15.618 & .270 & .929 & .009 \\
\hline & $\begin{array}{l}\text { perceived } \\
\text { parental pressure }\end{array}$ & 49.309 & 5 & 9.862 & .302 & .911 & .010 \\
\hline
\end{tabular}

It can be discovered that father's occupation, mother's occupation, mother's education, and parents' income have significant impact on both test anxiety and perceived parental pressure $(p<.05)$. Father's education, the interaction of father's occupation and mother's occupation, and the interaction of father's education and mother's education do not have significant effect on either test anxiety or perceived parental pressure $(p>.05)$. As for the significant Factors, all but parents' income have greater Partial Eta Squared $\left(\eta_{\mathrm{p}}{ }^{2}\right)$ for test anxiety than for perceived parental pressure, which demonstrates that most of the significant Factors contribute more to this model in relation with test anxiety than in relation with perceived parental pressure. According to $\eta_{\mathrm{p}}{ }^{2}$, the Factor which has the greatest contribution to the model in relation with test anxiety is father's occupation $\left(\eta_{\mathrm{p}}{ }^{2}=.138\right)$ and the Factor which has the greatest contribution to the model in relation with perceived parental pressure is parents' income $\left(\eta_{\mathrm{p}}{ }^{2}=.112\right)$. Among the insignificant Factors and interactions of Factors, the interaction of father's occupation and mother's occupation has even greater $\eta_{p}{ }^{2}$ for both test anxiety $\left(\eta_{p}{ }^{2}=.068\right)$ and perceived parental pressure $\left(\eta_{\mathrm{p}}{ }^{2}=.047\right)$ than mother's education, a significant Factor, has $\left(\eta_{\mathrm{p}}{ }^{2}=.054\right.$ and .049$)$. Since the $\eta_{\mathrm{p}}{ }^{2}$ statistic may report the "practical" significance of each Factor (Ferguson, 2009), based upon the "ratio" of the variation accounted for by the effect to the sum of the variation accounted for by the effect and the variation left to error, we consider that the interaction of father's occupation and mother's occupation, or in other words "parents' occupations", may have practically significant impact on both test anxiety and perceived parental pressure.

The discovery from the multivariate analysis of variance above can also be reflected in the Pearson correlations 
between the Factors and the two Dependent Valuables respectively, which are shown in Table 4.

Table 4. Correlations between factors and dependent valuables

\begin{tabular}{llrrrrr}
\hline & $\begin{array}{r}\text { father's } \\
\text { occupation }\end{array}$ & $\begin{array}{r}\text { mother's } \\
\text { occupation }\end{array}$ & $\begin{array}{r}\text { father's } \\
\text { education }\end{array}$ & $\begin{array}{r}\text { mother's } \\
\text { education }\end{array}$ & $\begin{array}{r}\text { parents' } \\
\text { income }\end{array}$ \\
\hline test anxiety & Pearson Correlation & $.280^{* *}$ & $.324^{* *}$ & .104 & $.139^{*}$ & $.340^{* *}$ \\
& $p$ (2-tailed) & .000 & .000 & .074 & .017 & .000 \\
& $N$ & 294 & 294 & 294 & 294 & 294 \\
perceived & Pearson Correlation & $.307^{* *}$ & $.365^{* *}$ & $.164^{* *}$ & $.208^{* *}$ & $.435^{* *}$ \\
parental & $p$ (2-tailed) & .000 & .000 & .005 & .000 & .000 \\
pressure & $N$ & 294 & 294 & 294 & 294 & 294 \\
\hline
\end{tabular}

The results of the correlations are mostly consistent with those of the multivariate analysis of variance. All significant Factors in the multivariate analysis of variance can also be found to have significant positive correlations with the two Dependent Valuables respectively. The correlation between father's education and perceived parental pressure is significant, which is an exception, since the multivariate analysis of variance fails to justify father's education's significant impact on perceived parental pressure.

A Sobel test is further conducted to test the significance of mediation effect of perceived parental pressure on the relationship between significant Factors and test anxiety. According to the results of Sobel Test (Sobel, 1982), the $p$-values for the mediation effects of perceived parental pressure on the relationship between significant Factors and test anxiety are all much lower than .05 , which demonstrates the fact that perceived parental pressure plays a significant role of mediator between most parent's socioeconomic status Factors and test anxiety. Table 5 shows the results of those Sobel tests.

Table 5. Sobel tests of significance of mediation relationships

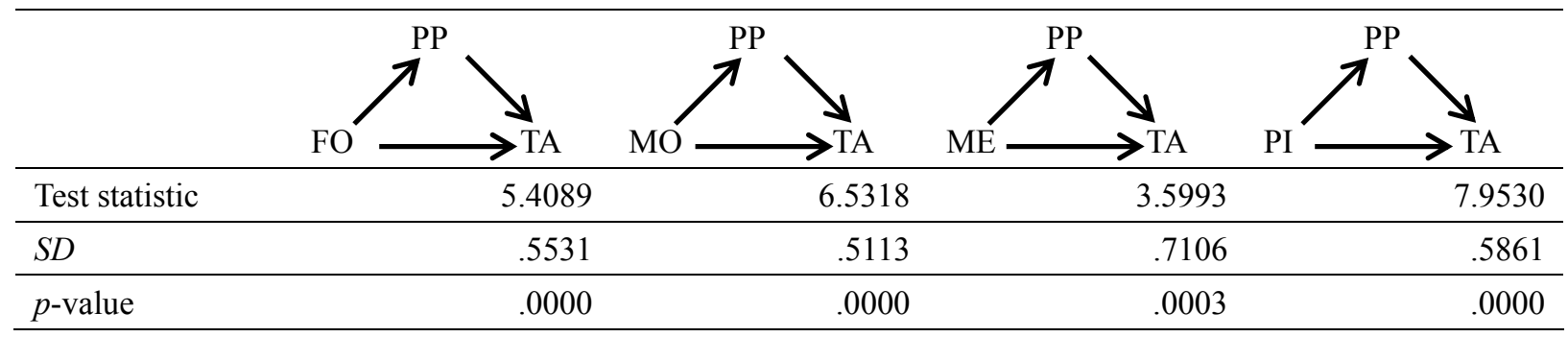

Description: $\mathrm{FO}=$ father occupation, $\mathrm{MO}=$ mother occupation, $\mathrm{ME}=$ mother education, $\mathrm{PI}=$ parents' income, $\mathrm{PP}=$ parental pressure, $\mathrm{TA}=$ test anxiety.

\section{Discussion}

This study discovers that there exists a great impact of perceived parental pressure on test anxiety. According to the regression analysis between perceived parental pressure and test anxiety, high degree of linear fit is demonstrated since the regression model can explain more than $70 \%$ of the variations in test anxiety $\left(R^{2}=.741\right)$, which is much higher than the regression data obtained in the study conducted by Pang (1991) among American students $\left(R^{2}=.20\right)$. The impact can also be reflected in the high correlation between perceived parental pressure and test anxiety $(r=.861, p=.000)$. The data are higher than those in the similar research (Putwain, Woods, \& Symes, 2010) conducted among British students in which the correlations were between .17 and .29. The high correlation observed in this study among Chinese students also confirms the fact that Chinese students perceive more parental pressure from their parents and thus are more stressed for test situations because their parents place greater importance on academic achievement as a means to achieve family glory, which results in constant involvement and monitoring of their children. 
Although the interaction of father's occupation and mother's occupation fails to have a significant impact on test anxiety and perceived parental pressure according to the $p$-value, father's occupation and mother's occupation are observed to have significant impact on both test anxiety and perceived parental pressure respectively. Since the interaction of father's occupation and mother's occupation has even greater $\eta_{\mathrm{p}}{ }^{2}$ for both test anxiety and perceived parental pressure than mother's education, a significant Factor, has, we consider that the interaction of father's occupation and mother's occupation, or in other words "parents' occupations", has practically significant impact on both test anxiety and perceived parental pressure. Therefore, parents' occupation and income can significantly influence both test anxiety and perceived parental pressure regardless of which parent is concerned with. The Factors with the greatest contribution to the multivariate analysis model also have relations with occupation or income. They are father's occupation which has the greatest contribution to the model in relation with test anxiety $\left(\eta_{\mathrm{p}}{ }^{2}=.138\right)$ and parents' income which has the greatest contribution to the model in relation with perceived parental pressure $\left(\eta_{\mathrm{p}}{ }^{2}=.112\right)$. The finding reflects the fact that in China today to improve economic condition is the utmost important reason why parents constantly monitor their children's academic progress. Since the coding of the three Factors (father's occupation, mother's occupation, and parents' income), and the Dependent Valuables (test anxiety and perceived parental pressure) are all positively correlated, it can be deduced that the lower the income and the more elementary the occupations, the higher test anxiety and perceived parental pressure the students may experience. It can be deduced from the correlations that the discrepancies of income and social status are quite distinct in China, which may promote the parents of lower income and social status to urge their children to study harder so as to catch up with richer families and in turn to cause more test anxiety in their children.

The data about parents' education which includes father's education and mother's education are not so consistent. On the one hand, father's education fails to have a significant effect on either test anxiety or perceived parental pressure according to the $p$-value. On the other hand, mother's education has a significant effect on both test anxiety and perceived parental pressure according to the $p$-value. The finding reflects the fact that mothers in China usually play a more important role than fathers on monitoring their children's academic progress so that children usually perceive more parental pressure from their mothers. Since the coding of mother's education and the Dependent Valuables (test anxiety and perceived parental pressure) are all positively correlated, it can be deduced that the lower education level mothers have, the higher test anxiety and perceived parental pressure the students may experience. It can be deduced from the correlations that higher levels of education may offset the influence of traditional parental views in China so that mothers with higher levels of education tend to be more liberal and give their children less parental pressure and in turn to reduce test anxiety in their children, and vice versa. Although mother's education has a significant effect on both test anxiety and perceived parental pressure according to the $p$-value, mother's education has smaller $\eta_{p}^{2}$ for either test anxiety or perceived parental pressure. The contradictory phenomenon shows that education is not the most important factor of parent's socioeconomic status which can affect test anxiety and perceived parental pressure greatly probably because people in China today are more practical and hold that family glory mainly comes from high income and social status instead of high level of education. The weak impact of parents' education can also be reflected in the fact that the interaction of father's education and mother's education not only fails to have significant effect on either test anxiety or perceived parental pressure but also has very small $\eta_{\mathrm{p}}{ }^{2}$ for either test anxiety or perceived parental pressure.

According to the results of the Sobel Test, there exists a mediation relationship among parent's socioeconomic status, perceived parental pressure and test anxiety, in which perceived parental pressure plays the role of mediator. The mediation relationship is shown in Figure 1.

The finding based on the Soble Test can be reflected in the multivariate analysis of variance in which we can find that among the significant Factors, all but parents' income have greater $\eta_{\mathrm{p}}{ }^{2}$ for test anxiety than for perceived parental pressure. That is to say, almost all significant Factors had greater impact on test anxiety than on perceived parental pressure. Since the impact of perceived parental pressure on test anxiety (impact of path B) as observed in the regression analysis is not estimated in the multivariate analysis of variance, the impact of the Factors on test anxiety estimated in the multivariate analysis of variance should be the combination of the strength of path C and the product of paths coefficients A and B. In path C, test anxiety is caused by student's own beliefs and values on parent's socioeconomic status, while in path B, test anxiety is caused by parents' pressure and monitoring. Since the impact of path A is transformed to the impact of path B through the mediator perceived parental pressure, it is quite reasonable that the impact of the Factors on test anxiety estimated in the multivariate analysis of variance is greater than the impact of the Factors on perceived parental pressure (impact of path A). 
This mediation relationship can also be reflected in the phenomenon that all Factors have higher correlations with perceived parental pressure than with test anxiety in that the lower correlations between the Factors and test anxiety may only represent the strength of path $\mathrm{C}$.

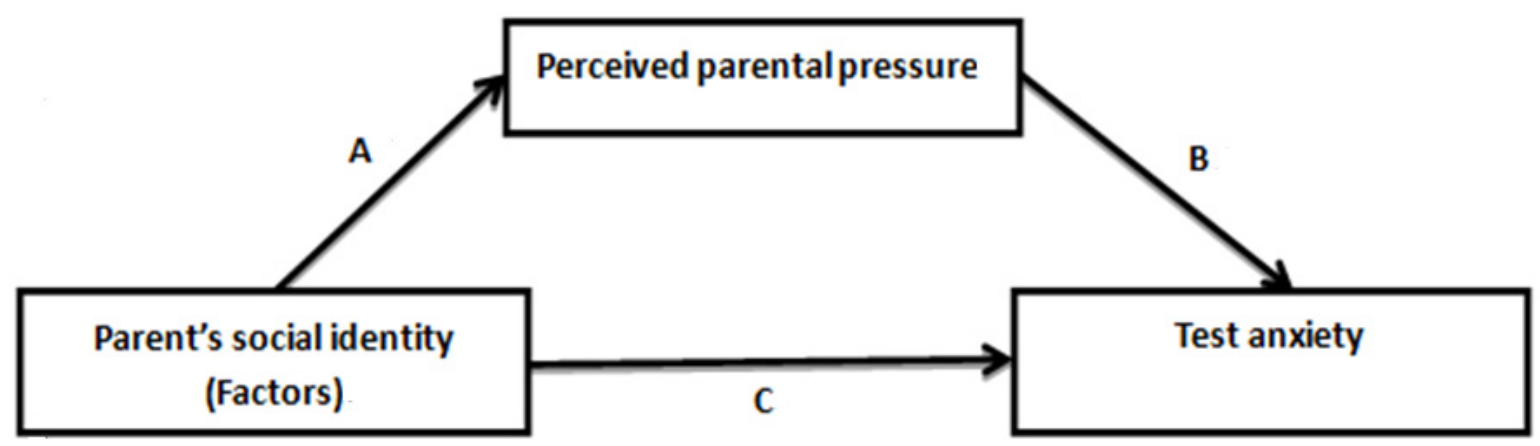

Figure 1. Mediation relationship among parent's socioeconomic status, perceived parental pressure and test anxiety

\section{Conclusion}

By conducting empirical researches among Mainland Chinese high school students, the three hypotheses of this study are partially verified. First, perceived parental pressure has significant impact on test anxiety. Second, parents' occupations, parents' income and mother's education have significant impact on perceived parental pressure. Third, parents' occupations, parents' income and mother's education have significant impact on test anxiety. In the analysis, sufficient evidences are discovered to support the notion that the ethic stressing family glory, filial piety, and material success still prevails in China and has become a major source of perceived parental pressure and test anxiety in China.

Another finding of the study is that there may exist a mediation relationship among parent's socioeconomic status, perceived parental pressure, and test anxiety. This relationship suggests ways of coping with test anxiety. Since the Chinese ethic stressing family glory and material success cannot be changed easily, the negative impact of parent's socioeconomic status on test anxiety can only be reduced by controlling perceived parental pressure, the mediator variable. Therefore, efforts can be made to transform parental pressure to parental support by encouraging parents to provide their children with more emotional support, caring, concern, affection, kindness and tenderness $(\mathrm{Ho}, 1986)$ on the one hand, and help their children acquire problem-solving strategies and foster the development of their children's competency expectation (Hock, 1992) on the other hand so as to reduce test anxiety in their children and optimize their test performance.

\section{References}

Baumrind, D. (1978). Parental disciplinary patterns and social competence in children. Youth \& Society, 9, 239-76. http://dx.doi.org/10.1177/0044118X7800900302

Bodas, J., \& Ollendick, T. H. (2005). Test anxiety: a cross-cultural perspective. Clinical Child and Family Psychology Review, 8, 65-88. http://dx.doi.org/10.1007/s10567-005-2342-x

Campbell, J. R. (1994). Differential socialization in mathematics achievement: Crossnational and cross-cultural perspectives. International Journal of Education Research, 21, 685-696. http://dx.doi.org/10.1016/0883-0355(94)00003-4

Campbell, J. R., \& Mandell, F. (1990). Connecting math achievement to parental influences. Contemporary Educational Psychology, 15, 64-74. http://dx.doi.org/10.1016/0361-476X(90)90006-M

Chan, D. W. (1995). Depressive symptoms and coping strategies among Chinese adolescents in Hong Kong. Journal of Youth and Adolescence, 24, 267-279. http://dx.doi.org/10.1007/BF01537596

Crystal, D. S., Chen, C., Fuligni, A. J., Stevenson, H. W., Hsu, C., Ko, H., Kitamura, S., \& Kimura, S. (1994). Psychological maladjustment and academic achievement: A cross-cultural study of Japanese, Chinese, and 
$\begin{array}{llllll}\text { American high school students. Child Development, } & \text { 65, }\end{array}$ http://dx.doi.org/10.1111/j.1467-8624.1994.tb00780.x

Diona, K. L., \& Toner, B. B. (1988). Ethnic differences in test anxiety. The Journal of Social Psychology, 128, 165-172. http://dx.doi.org/10.1080/00224545.1988.9711359

Ferguson, C. J. (2009). An effect size primer: A guide for clinicians and researchers. Professional Psychology Research and Practice, 40, 532-538. http://dx.doi.org/10.1037/a0015808

Ho, D. Y. F. (1986). Chinese patterns of socialization: A critical review. In M.H. Bond (Eds.), The Psychology of the Chinese People (pp. 171-212). New York: Oxford University Press.

Hock, M. (1992). Exchange of aversive communicative acts between mother and child as related to perceived child-rearing practices and anxiety of the child. In K. Hagtvet \& T. Johnsen (Eds.), Advances in Test Anxiety Research (Vol. 7, pp. 156-174). Amsterdam: Swets and Zeitlinger.

Hopko, D. R., Hunt, M. K., \& Armento, M. E. (2005). Attentional task aptitude and performance anxiety. International Journal of Stress Management, 12, 389-408. http://dx.doi.org/10.1037/1072-5245.12.4.389

Lin, C. C., \& Fu, V. R. (1990). A comparison of child-rearing practices among Chinese, immigrant Chinese, and $\begin{array}{lllll}\text { Caucasian-American } \quad \text { parents. } & \text { Child }\end{array}$ http://dx.doi.org/10.1111/j.1467-8624.1990.tb02789.x

Maccoby, E, E., \& Martin, J. A. (1983). Socialization in the context of the family: Parent-child interaction. In E. M. Etherington (Eds.), Handbook of Child Psychology: Socialization, Personality and Social Development (pp. 1-101), New York: Wiley.

Pang, V. O. (1991). The relationship of test anxiety and math achievement to parental values in Asian-American and European-American middle school students. Journal of Research \& Development in Education, 24, $1-10$.

Pekrun, B., Goetz, T., Perry, R. P., Kramer, K., Hochstadt, M., \& Molfenter, S. (2004). Beyond test anxiety: development and validation of the test emotions questionnaire (TEQ). Anxiety, Stress, and Coping, 17, 287-316. http://dx.doi.org/10.1080/10615800412331303847

Putwain, D. W. (2007). Test anxiety in UK schoolchildren: Prevalence and demographic patterns. British Journal of Educational Psychology, 77, 579-593. http://dx.doi.org/10.1348/000709906X161704

Putwain, D. W. (2009). Assessment and examination stress in key stage 4. British Educational Research Journal, 35, 391-411. http://dx.doi.org/10.1080/01411920802044404

Putwain, D. W., Woods, K. A., \&. Symes, W. (2010). Personal and situational predictors of test anxiety of students in post-compulsory education. British Journal of Educational Psychology, 80, 137-160. http://dx.doi.org/10.1348/000709909X466082

Rocklin, T., \& Thompson, J. M. (1985). Interactive effects of test anxiety, test difficulty, and feedback. Journal of Experimental Psychology, 77, 368-372. http://dx.doi.org/10.1037/0022-0663.77.3.368

Sarason, I. G. (1984). Stress, anxiety, and cognitive interference: Reactions to tests. Journal of Personality and Social Psychology, 46, 929-938. http://dx.doi.org/10.1037/0022-3514.46.4.929

Singh, A., \&. Broota, A. (1992). Socio-personal variables and examination anxiety. Journal of the Indian Academy of Applied Psychology, 18, 73-78.

Spielberger, C. D. (1980). Test Anxiety Inventory: Preliminary Professional Manual. Palo Alto, CA: Consulting Psychology Press.

Sobel, M. E. (1982). Asymptotic confidence intervals for indirect effects in structural equation models. Sociological Methodology, 13, 290-312.

Soper, D. S. (2012). Sobel Test Calculator for the Significance of Mediation (Online Software). Retrieved from http://www.danielsoper.com/statcalc3

Ye, R., \& Rocklin, T. (1988). A cross-cultural research on test anxiety. Psychological Science Report, 3, 25-29.

Zeidner, M. (1998). Test Anxiety: The State of the Art. New York: Plenum.

\section{Note}

Note 1. The International Standard Classification of Occupations (ISCO) is an International Labor Organization 
(ILO) classification structure for organizing information on labor and jobs. It is part of the international family of economic and social classifications of the United Nations. The current version, known as ISCO-08, was published in 2008 . 